\title{
Mitochondrial DNA Hypomethylation Is a Biomarker Associated with Induced Senescence in Human Fetal Heart Mesenchymal Stem Cells
}

\author{
Dehai Yu, ${ }^{1,2}$ Zhonghua Du, ${ }^{1,2}$ Lingling Pian, ${ }^{1,2}$ Tao Li, ${ }^{2}$ Xue Wen, ${ }^{1}$ Wei Li, ${ }^{1}$ Su-Jeong Kim, ${ }^{3}$ \\ Jialin Xiao, ${ }^{3}$ Pinchas Cohen, ${ }^{3}$ Jiuwei Cui, ${ }^{1}$ Andrew R. Hoffman, ${ }^{2}$ and Ji-Fan Hu ${ }^{1,2}$ \\ ${ }^{1}$ Stem Cell and Cancer Center, The First Bethune Hospital, Jilin University, Changchun, Jilin 130061, China \\ ${ }^{2}$ Stanford University Medical School, Palo Alto Veterans Institute for Research, Palo Alto, CA 94304, USA \\ ${ }^{3}$ Leonard Davis School of Gerontology, University of Southern California, Los Angeles, CA 90089, USA
}

Correspondence should be addressed to Pinchas Cohen; hassy@usc.edu, Jiuwei Cui; cuijw@jlu.edu.cn, Andrew R. Hoffman; arhoffman@stanford.edu, and Ji-Fan Hu; jifan@stanford.edu

Received 18 October 2016; Revised 5 January 2017; Accepted 16 January 2017; Published 6 April 2017

Academic Editor: Martin Stimpfel

Copyright (C) 2017 Dehai Yu et al. This is an open access article distributed under the Creative Commons Attribution License, which permits unrestricted use, distribution, and reproduction in any medium, provided the original work is properly cited.

Background. Fetal heart can regenerate to restore its normal anatomy and function in response to injury, but this regenerative capacity is lost within the first week of postnatal life. Although the specific molecular mechanisms remain to be defined, it is presumed that aging of cardiac stem or progenitor cells may contribute to the loss of regenerative potential. Methods. To study this aging-related dysfunction, we cultured mesenchymal stem cells (MSCs) from human fetal heart tissues. Senescence was induced by exposing cells to chronic oxidative stress/low serum. Mitochondrial DNA methylation was examined during the period of senescence. Results. Senescent MSCs exhibited flattened and enlarged morphology and were positive for the senescence-associated beta-galactosidase (SA- $\beta-\mathrm{Gal}$ ). By scanning the entire mitochondrial genome, we found that four CpG islands were hypomethylated in close association with senescence in MSCs. The mitochondrial COX1 gene, which encodes the main subunit of the cytochrome c oxidase complex and contains the differentially methylated CpG island 4, was upregulated in MSCs in parallel with the onset of senescence. Knockdown of DNA methyltransferases (DNMT1, DNMT3a, and DNMT3B) also upregulated COX1 expression and induced cellular senescence in MSCs. Conclusions. This study demonstrates that mitochondrial CpG hypomethylation may serve as a critical biomarker associated with cellular senescence induced by chronic oxidative stress.

\section{Introduction}

The adult mammalian heart has traditionally been viewed as a nonregenerative organ as it retains very minimal regenerative potential. Following cardiac injury, as in the case of myocardial infarction, the heart fails to replace the vast majority of lost or damaged cardiomyocytes. Instead, the heart heals with scar tissue, leading to a contractile defect of the organ and ultimately heart failure [1]. However, the hearts of oneday-old mouse retain full regenerative potential and are able to restore normal anatomy and function after cardiac injury [2]. This regenerative capacity of the neonatal mouse heart, however, becomes lost within the first week of postnatal life. Decreases in cardiac stem or progenitor cells could be one of the determining factors for the loss of regenerative capacity in this aging process [3].

Mesenchymal stem cells (MSCs) have attracted great interest as a promising regenerative therapeutic for many human diseases, primarily because of their capacity for selfrenewal, multilineage differentiation, and immune modulation [9-13]. MSCs derived from fetal heart (c-MSCs, HMSCs) have the potential to differentiate into cardiomyocytes, endothelial cells, and smooth muscle cells [3, 14-16]. Engraftment of fetal cardiac MSCs improves cardiac function and can repair myocardium in a rat model of myocardial infarction [15]. However, to serve as a useful regenerative therapy, MSCs isolated from patients need to be expanded ex vivo [17]. MSCs have a limited lifespan in cell culture, 
and after a few passages of expansion, the cells enter the senescent state, leading to the reduction in self-renewal ability and differentiation potential $[18,19]$. Moreover, the self-renewal potential of MSCs is significantly reduced with aging. Like many primary cells in culture, MSCs show decreased proliferation and increased apoptosis as the age of the donor animal or human [20-24]. As MSCs approach senescence, their proliferation slows significantly, leading to a decrease in differentiation potential [25]. Therefore, it is critical to understand the mechanisms that control replicative senescence in MSCs.

Replicative senescence, a process that places cells in permanent proliferative arrest in response to various stressors, is a potentially important contributor to aging and age-related disease. It is clear that cellular senescence is associated with an array of epigenetic modifications that may be responsible for changes in gene expression that ultimately lead to catabolic and degenerative processes. Mitochondrial DNA (mtDNA) damage has long been implicated in the aging process [26]. A number of mitochondrial signaling pathways can induce cellular senescence [27]. However, the role of mitochondrial epigenetics has largely been unexplored. In fact, the importance and relevance of mitochondrial epigenetics in aging has been controversial [28], primarily because of the difficulty of studying the relatively small mitochondrial genome in the context of the far larger nuclear genome.

Methylation of mtDNA in a variety of tissues varies with aging, disease states, environmental exposure, and certain drugs. In addition to 5-methylcytosine, a so-called "sixth base," 5-hydroxymethylcytosine has also been identified in mtDNA, where its abundance changes during aging independently of 5-methylcytosine levels [29]. It has been suggested that mtDNA methylation might become a next-generation biomarker for aging [30]. Currently, we know very little about the role of mtDNA methylation in the aging-related dysfunction of cardiac stem or progenitor cells. To gain insight regarding the role of mitochondrial epigenetics in senescence, we induced senescence in MSCs cultured from human fetal heart tissues and examined epigenetic mechanisms that may be associated with cellular aging in MSCs.

\section{Materials and Methods}

2.1. Isolation of MSCs. Isolation of MSCs from fetal heart tissues was performed following the method as described previously $[3,16]$ with some modifications. Briefly, fetal heart tissues from days 45-67 of embryos were obtained from Human Tissue Network (Central Laboratory for Human Embryology Tissue, University of Washington, WA) in phosphate-buffered saline (PBS). Upon arrival, the tissues were minced with a razor into small pieces. To avoid destroying the cardiac stem cell niche, we did not digest the tissue with collagenase. Instead, the minced heart tissues were directly seeded on a $10 \mathrm{~cm}$ plate with a small amount of DMEM (2-3 ml) containing 10\% fetal calf serum (FCS) and antibiotics and were cultured at $37^{\circ} \mathrm{C}$ in a $5 \% \mathrm{CO}_{2}$ humidified atmosphere. After the heart tissue became attached to the plate, a small amount of fresh medium was added to the plate without disturbing the tissues on a daily basis. After 5-7 days,
MSCs began to migrate out from the heart explants and the MSCs were collected for further expansion. MSCs at passages 3-5 were used for analysis. MSCs from fetal skin tissues were isolated using the same approach and were used in parallel with HMSCs in the study. The experimental protocol was approved by the Institutional Review Board/Stem Cell Research Oversight Panel at Stanford University.

2.2. Characterization of MSCs. The MSCs cultured from fetal heart (HMSCs) were characterized by flow cytometry using stem cell markers as previously described [31]. Cells were collected at a concentration of $1 \times 10^{6}$ cells $/ \mathrm{ml}$ in phosphatebuffered saline (PBS) containing 0.1\% BSA. Cells were incubated at $4^{\circ} \mathrm{C}$ with antibodies against MSC-markers (CD90, CD73, and CD105), hematopoietic cell markers (CD45, CD34, CD14, and CD19), and receptors for extracellular matrix (CD29, CD44) and major histocompatibility (HLADR) (all from BD Biosciences, CA). Thirty minutes after antibody incubation, cells were washed and suspended in $300 \mu \mathrm{L}$ PBS. Flow cytometry was performed using FACSCAria III Cell Sorter (BD Biosciences, CA) [32-35].

2.3. Differentiation of MSCs. The differential potential of the isolated MSCs into adipogenic and osteogenic lineages was performed as described previously [32-35]. After induction, cells were stained with the Oil Red $\mathrm{O}$ and Alizarin Red (Sigma, USA) to detect the presence of neutral lipid vacuoles in differentiated adipocytes and calcium deposition in osteocytes, respectively.

2.4. Induced Senescence in MSCs. To mimic the replicative senescence seen in MSCs $[36,37]$, we adopted a new approach by chronically exposing cells to low oxidative stress and a low serum environment. Specifically, HMSCs at passages 3-5 at approximately $50 \%$ confluence were continuously exposed to low concentration of hydrogen peroxide $\left(50 \mu \mathrm{M} \mathrm{H}_{2} \mathrm{O}_{2}\right)$ in DMEM supplemented with 5\% FBS. Using this approach, MSCs exhibited a typical senescence-like morphology after 23 passages. Cells were collected for RNA-Seq analysis (Beijing Honor Tech Co., Ltd., Beijing, China).

2.5. Staining of Senescence-Associated $\beta$-Galactosidase. Cellular senescence was quantitated by measuring the activity of SA- $\beta-$ Gal as previously described $[38,39]$. MSCs were collected and fixed using 3\% formaldehyde for 3-5 min at room temperature. After washing with PBS, cells were incubated at $37^{\circ} \mathrm{C}$ with freshly prepared senescence-associated SA- $\beta$-Gal staining solution: $1 \mathrm{mg} / \mathrm{ml}$ 5-bromo-4-chloro-3indolyl P3-D-galactoside (X-Gal), $40 \mathrm{mM}$ citric acid/sodium phosphate, $\mathrm{pH} 6.0,5 \mathrm{mM}$ potassium ferrocyanide, $5 \mathrm{mM}$ potassium ferricyanide, $150 \mathrm{mM} \mathrm{NaCl}$, and $2 \mathrm{mM} \mathrm{MgCl} 2$. After overnight incubation, cells with the SA- $\beta$-Gal staining were assessed using a microscope-mounted camera.

2.6. Detection of Telomere Length in Aging Cells. The relative length of telomeres was estimated by quantitative PCR as previously reported [40, 41]. Briefly, genomic DNA was extracted with Qiagen DNeasy Blood \& Tissue Kit (Qiagen, 
CA, USA). After dilution, $35 \mathrm{ng} / \mu \mathrm{l}$ DNA was heated at $95^{\circ} \mathrm{C}$ for $5 \mathrm{~min}$ and chilled on ice for $5 \mathrm{~min}$. The DNA samples were placed in a $20 \mu \mathrm{l}$ real-time qPCR reaction system containing $10 \mu \mathrm{l} 2 \times$ SYBR premixed buffer (Roche, Shanghai, China), $2 \mu \mathrm{l}$ forward and reverse primers. The sequence of primers includes (1) telomere forward: $5^{\prime}$-GGTTTTTGAGGGTGAGGGTGAGGGTGAGGGTGAGGGT- $3^{\prime} \quad(100 \mathrm{nM})$ and reverse: $5^{\prime}$-TCCCGACTATCCCTATCCCTTCCCTATCCCTATCCCTA-3' $(300 \mathrm{nM})$; and (2) $\beta$-globin forward: $5^{\prime}$ - GCTTCTGACACAACTGTGTTCACTAGC-3' (150 nM) and reverse: $5^{\prime}$-CACCAACTTCATCCACGTTCACC- $3^{\prime}$ $(150 \mathrm{nM})$. The PCR amplification process was one cycle at $95^{\circ} \mathrm{C} 10 \mathrm{~min}$ and 40 cycles at $95^{\circ} \mathrm{C}$ for $15 \mathrm{~s}, 56^{\circ} \mathrm{C}$ for $30 \mathrm{~s}$, and $72^{\circ} \mathrm{C} 30 \mathrm{~s}$ (ABI SepOnePlus, Beijing, China). The telomere length was estimated by the relative ratio between the copies of telomere and the copies of $\beta$-globin (T/S). T/S value is calculated by $2^{-\Delta \Delta \mathrm{Ct}}[40,41]$.

2.7. Gene Expression of the Senescence and the Cardiac Development Pathways. Comparison of the senescence and cardiac development pathway genes was performed by RNA-Seq [42]. Total RNA was isolated using Qiazol (Qiagen, CA) and used for indexed library preparation using Illumina's TruSeq RNA Sample Prep Kit v2. Libraries were sequenced using a HiSeq4000 (Illumina) and yielded approximately 34 million reads with a length of $150 \mathrm{bp}$ per sample. Gene counts were normalized to the values of Reads Per Kilobase of transcript per Million mapped reads (RPKM). KEGG pathways were selected as significantly regulated if the corrected $P$ values were smaller than 0.05 (Beijing Honor Tech Co.,Ltd., Beijing, China).

2.8. Measurement of mtDNA Methylation by COBRA. Mitochondrial and total cellular DNAs were extracted by DNeasy Blood \& Tissue Kit (Qiagen, CA) and treated by sodium bisulfite using EZ DNA Methylation ${ }^{\mathrm{TM}}$ Kit (Zymo, CA), following the protocol provided by the manufacturer. Initially, we obtained mtDNA from isolated mitochondria and treated the DNA with sodium bisulfite for cloning sequencing. Later, we found that the protocol could be greatly simplified by simply using total genomic DNA with PCR primers that are specific for mitochondrial DNA.

Bisulfite-treated DNA was amplified by polymerase chain reaction (PCR) under liquid wax in a $6 \mu \mathrm{l}$ reaction containing $2 \mu \mathrm{l}$ of $3 \times$ Klen-Taq I Mix, $2 \mu \mathrm{l}$ template DNA, and $1 \mu \mathrm{l}$ of each $2.5 \mu \mathrm{M}$ primer. After incubation at $95^{\circ} \mathrm{C}$ for $5 \mathrm{~min}$, DNA was amplified by 38 cycles of $95^{\circ} \mathrm{C}$ for $20 \mathrm{~s}, 62^{\circ} \mathrm{C}$ for $20 \mathrm{~s}$ of annealing, and $72^{\circ} \mathrm{C}$ for $20 \mathrm{~s}$ of extension and finally with extension at $72^{\circ} \mathrm{C}$ for $2 \mathrm{~min}$. Methylation PCR primers sequences are listed in Table S1 (see Table S1 in the Supplementary Material available online at https://doi.org/10.1155/2017/1764549).

The status of mtDNA methylation was determined by restriction enzyme digestion. PCR DNAs were digested by Taq I at $65^{\circ} \mathrm{C}$ for $2 \mathrm{~h}$ or HpyCH4IV at $37^{\circ} \mathrm{C}$ for $2 \mathrm{~h}$ and separated on 3\% agarose gel. Taq I recognizes the TCGA site and HpyCH4IV digests the ACGT site. After treatment with sodium bisulfate, unmethylated cytosines were converted to uracils $[43,44]$. As a result, methylated mtDNA will be digested by the restriction enzymes. In contrast, unmethylated mtDNAs will be converted to TTGA and ATGT, which are not digested by Taq I and HpyCH4IV, respectively. The methylated and unmethylated bands were scanned for quantitation.

\subsection{Knockdown of DNMTs by RNA Interference Lentiviruses.} Two different RNA interference oligonucleotides targeting each DNMT gene were driven by $\mathrm{H} 1$ and U6 promoters, respectively, and were jointly subcloned into pGreenpuro lentiviral vector by PCR. The oligonucleotide sequences targeting DNMT1, DNMT3a, and DNMT3b are as follows: DNMT1 (A): 5'-GCCCAATGAGACTGACATCAA-3'; DNMT1 (B): 5'-GGAACCAAGCAAGAAGTGA-3'; DNMT3a (A): $5^{\prime}$-AGCGGGCAAAGAACAGAAG-3'; DNMT3a (B): $5^{\prime}$-CCAGATGTTCTTCGCTAATAA- ${ }^{\prime}$; DNMT3b (A): $5^{\prime}$-CCTGTCATTGTTTGATGGCAT-3'; DNMT3b (B): 5'-CCATGCAACGATCTCTCAAAT- $3^{\prime}$. The scramble control sequence is $5^{\prime}$-GCTTCAATTCGCGCACCTA- $3^{\prime}$.

For viral packaging, $293 \mathrm{~T}$ cells were transfected with $2 \mu \mathrm{g}$ of each lentiviral expression construct. Transfections were done in six-well plates using Lipofectamine 2000 (Invitrogen, USA). Viral supernatants were collected at 24 and $48 \mathrm{~h}$ after transfection. After addition of polybrene $\left(8 \mu \mathrm{g} \mathrm{ml}^{-1}\right)$, the supernatants were placed on the cultured HMSCs cells. Cells were transfected twice to increase transfection efficiency.

2.10. RT-PCR Analysis. RT-PCR was used to quantitate the expression of genes related to senescence. Total RNA was extracted by TRIzol reagent (Sigma, MO) and was converted to cDNA by reverse transcription reaction as previously described $[45,46]$. We designed PCR primers as follows: $\beta$-actin: $5^{\prime}$-CAGGTCATCACCATTGGCAATGAGC-3' (forward) and $5^{\prime}$-CGGATGTCCACGTCACACTTCATGA-3' (reverse); caveolin-1: $5^{\prime}$-TCCCATCCGGGAACAGGGCAACAT- $3^{\prime}$ (forward) and $5^{\prime}$-GTCCCTTCTGGTTCTGCAATC-3' (reverse); P16: $5^{\prime}$-CGGATAATTCAAGAGCTAACAGGT-3' (forward) and $5^{\prime}$-GGCCTCCGACCGTAACTATTCGGT-3' (reverse); P21: $5^{\prime}$-GTGGACCTGTCACTGTCTTGTAC- $3^{\prime}$ (forward) and $5^{\prime}$-GCTTCCTCTTGGAGAAGATCAGC- ${ }^{\prime}$ (reverse); apolipoprotein: $5^{\prime}$-GGTCTCWGACAATGAGCTCCA-3 (forward) and $5^{\prime}$-TCCCAGAGGGCCATCATGGTC-3' (reverse); COX1: $5^{\prime}$-CAGCATGCCCCAGGATTTGTC-3' (forward) and $5^{\prime}$ CAKGTCCTGCTCCAGGGCAGC-3' (reverse, $\mathrm{K}=\mathrm{G} / \mathrm{T}$ ). The PCR amplification was composed of 1 cycle at $95^{\circ} \mathrm{C}$ for $5 \mathrm{~min}$ and 33 cycles at $95^{\circ} \mathrm{C} 20 \mathrm{~s}, 62^{\circ} \mathrm{C} 15 \mathrm{~s}$, and $72^{\circ} \mathrm{C} 15 \mathrm{~s}$ and ending with an extension cycle at $72^{\circ} \mathrm{C} 5 \mathrm{~min}$.

2.11. Measurement of COX1 Enzyme Activity. COX1 activity was determined by cellular staining for cytochrome $\mathrm{C}$ oxidase. MSCs $\left(1 \times 10^{6}\right)$ were plated in 6-well plate and were cultured for $24 \mathrm{hrs}$. Cells were rinsed 3 times with PBS and were dried in air. Cells were incubated for $15 \mathrm{~min}$ at $\mathrm{RT}$ in the preincubation medium $(50 \mathrm{mM}$ Tris- $\mathrm{HCl}, \mathrm{pH}$ 7.6; $0.29 \mathrm{M}$ sucrose; $2.2 \mathrm{mM}$ cobalt chloride) and were rinsed with buffer I ( $0.1 \mathrm{M}$ sodium phosphate $\mathrm{pH} 7.6 ; 10 \%$ sucrose). Cells were incubated for $4 \mathrm{hrs}$ at $37^{\circ} \mathrm{C}$ in $10 \mathrm{ml}$ incubation 
medium ( $\mathrm{pH} 7.4,0.1 \mathrm{M}$ sodium phosphate $\mathrm{pH} 7.6,10 \%$ sucrose, $10 \mathrm{mg}$ cytochrome C (Sigma, MO), $10 \mathrm{mg}$ DAB (3,3' diaminobenzidine) hydrochloride (Sigma, MO), and $2.0 \mathrm{mg}$ catalase (Sigma, MO)). Cells were rinsed once with buffer $\mathrm{I}$ and $5 \mathrm{~min}$ with $\mathrm{PBS}$, washed with $\mathrm{H}_{2} \mathrm{O}$ for $5 \mathrm{~min}$, and observed under microscope.

2.12. Statistical Analysis. Data were analyzed using SPSS software (version 16.0; SPSS, Inc., IL). Student's $t$-test or one-way ANOVA (Bonferroni test) was used to compare statistical differences for variables among treatment groups. The data were expressed as mean \pm SD. All experiments were performed in triplicate, and results were considered statistically significant at $P<0.05$.

\section{Results}

3.1. Multilineage Differentiation of Fetal Heart Mesenchymal Stem Cells. MSCs isolated from different tissues, despite their molecular congruence, exhibit strong biases in gene and protein expression, pathway activity, and lineage differentiation, suggesting the presence of "molecular memory of tissue origin" [14]. These conserved organ-specific functions may potentially render them more appropriate as cellular therapeutic agents for their organ of origin, particularly in "in situ reprogramming" or "in situ differentiation" models. Of note, the murine neonatal heart can regenerate and restore damaged sections resulting in the restoration of normal anatomy and function without scar formation, but this capacity is lost after one week of age [2]. We were interested to learn if epigenetic alterations in mitochondria DNA were involved in this aging process.

To define the potential epigenetic mechanisms underlying this cardiac aging, we cultured MSCs from human fetal heart tissues, which are presumed to maintain full regenerative potential. Adherent MSCs grew 8-12 days after the initial tissue seeding and were collected for phenotypic analysis using flow cytometry. We found that stem cell markers were universally expressed in isolated MSCs, including CD105, CD73, CD90, CD44, and CD29 (Figure 1(a)). Negative stem cell markers, including CD45, CD34, CD14, CD19, and HLA-DR, were expressed at very low levels. The isolated HMSCs could be differentiated into adipogenic and osteogenic lineages (Figure 1(b)). These data suggest that the MSCs cultured from fetal heart exhibited the potential of multilineage differentiation as previously reported $[3,14,16]$.

As tissue MSCs exhibit strong "molecular memory of tissue origin" [14], we used RNA-Seq to examine the pathway genes that are associated with cardiac development [4-8]. We found that genes involved in cardiac programing were also expressed in HMSCs, including AKT pathway, GATA family, and TBX family genes (Figure $1(\mathrm{c})$ ). These data suggest that these HMSCs may serve as an appropriate model to study cardiac aging.

3.2. Induction of Chronic Senescence in Mesenchymal Stem Cells. Two types of induced senescence have commonly been used to study aging in vitro, including replicative senescence
(RS) and stress-induced premature senescence (SIPS) [4749]. RS is characterized by progressive telomere shortening, which occurs at every cell division. Although it is an excellent mimic of the natural aging process, induction of senescence is very time-consuming. On the other hand, SIPS is induced by exposure to subcytotoxic stress, and cells undergo premature senescence without telomere shortening. SIPS is the most frequently used model in studying aging. However, cellular toxicity is encountered in this model, particularly by high concentrations of hydrogen peroxide. Therefore, SIPS may not be an appropriate model of in vivo pathophysiological aging in cardiac stem cells.

In this study, we established a novel model by combining the advantages of both RS and SIPS. In this model, we facilitated the occurrence of replicative senescence by a new "two-hit" approach. Fetal heart-derived MSCs (HMSCs) were exposed simultaneously to low doses of hydrogen peroxide $(50 \mu \mathrm{M})$ and to low serum $(5 \%)$ in cell culture. It was presumed that exposure to low dose of hydrogen peroxide would generate much less toxicity than that usually encountered in SIPS. Meanwhile, low serum exposure would accelerate the development of senescence. After combined exposure for 2-3 passages, we found that HMSCs exhibited flattened morphology and decreased cell proliferation. The treated MSCs stained positive for senescence-associated betagalactosidase (SA- $\beta$-Gal) activity (Figures $2(\mathrm{a})$ and $2(\mathrm{~b})$ ).

We then used PCR to quantitate senescence-related genes that have been previously reported $[38,39,50]$. We found that the caveolin-1 gene (CAV1) was upregulated in senescent MSCs (Figure 2(c)), although we did not detect a significant change in APO-J and OX1. P21 was also upregulated in parallel with cell senescence (Figure 2(d)). Future studies are needed to clarify the time point from the senescenceinducing stimulus when p53 and p21 start to be upregulated.

To further characterize the senescent cells, we measured telomere length using quantitative PCR. By comparing telomere length among the three models, it was clear that the senescent cells in our model had the telomere shortening similar to that seen in replicative senescent cells (Figure 2(e)). As expected, there was no significant change in telomere length in cells that were treated with high dose of hydrogen peroxide. In addition, using RNA-Seq we found that the pathways previously identified in replicative senescent cells $[42,51]$ were also activated in our senescent cells (Figures S1-S2). Together, these data suggest that our model carries a phenotype that is prone to replicative senescence.

\subsection{Cellular Senescence Is Associated with Differential Methy-} lation of mtDNA CPG Islands. To depict the epigenetic mechanism underlying cellular senescence, we used sodium bisulfite sequencing to assess DNA methylation in a total of $11 \mathrm{CpG}$ islands throughout the mitochondrial genome (Figure 3(a)). Using restriction enzymes to distinguish the methylated and unmethylated CpGs, we found that the mitochondrial genome was primarily unmethylated. Three CpG islands exhibited considerable mtDNA hypomethylation in senescent HMSCs, including CpG islands 4,1 , and 2 (Figure 3(b)). Similar mtDNA methylation pattern was also 


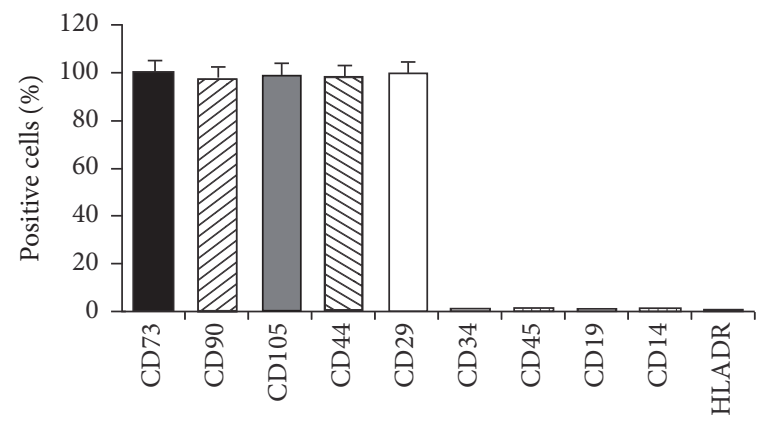

(a) Biomarkers in HMSCs

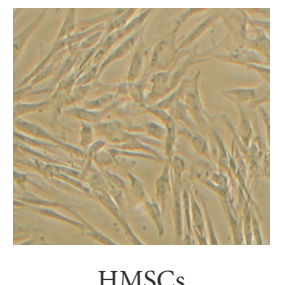

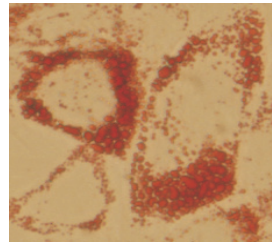

Adipogenic

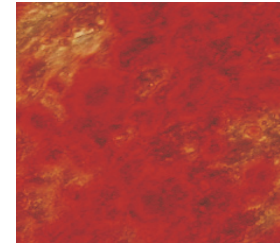

Osteogenic (b) Differentiation of HMSCs

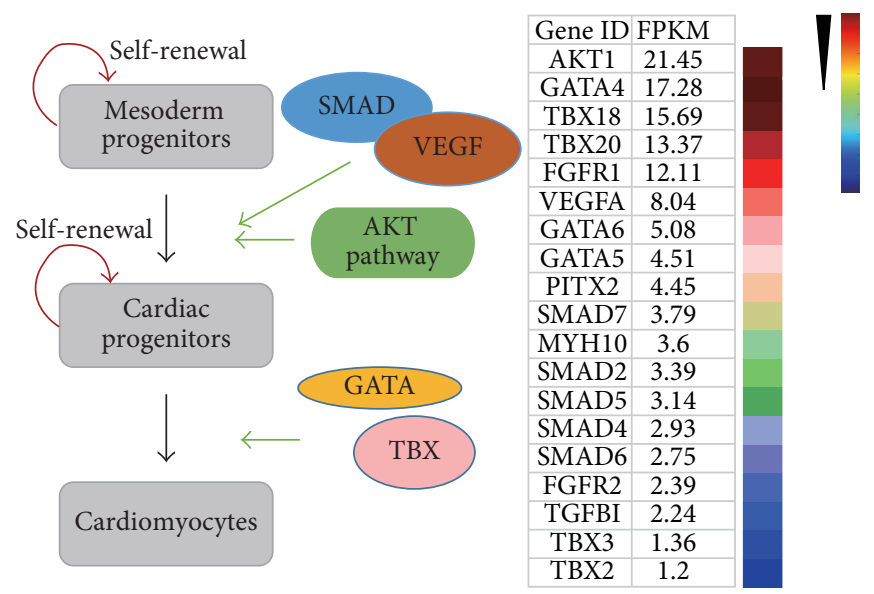

(c) Cardiac pathway genes

FIGURE 1: Characterization of human fetal heart-derived mesenchymal stem cells (HMSCs). (a) The profile of stem cell markers in cultured HMSCs. Immunophenotypes of MSCs were determined by flow cytometry using labeled antibodies specific for the indicated human surface antigens. (b) Differentiation potential of HMSCs. Cells were stained by Alizarin Red for calcium deposits during osteogenic differentiation. Adipogenic differentiation was detected by Oil Red O staining (200x). (c) The "molecular memory of cardiac origin" of HMSCs. Left panel: schematic diagram of the published cardiac stem cell pathways [4-8]. Right panel: expression of pathway genes in HMSCs. Total RNAs were isolated from HMSCs for RNA-Seq using a HiSeq4000 (Illumina). Colors represent from high (red) to low (blue) expression based on normalized FPKM values for each gene.

observed in SMSCs (Figure 3(c)). The remaining CpG islands, however, showed fewer differences between the control and senescent MSCs (Figures S3-S5). We also noticed the difference in mtDNA methylation in three CpG islands $(4,2$, and 1) between neonatal and adult skin fibroblasts (Figure 3(d)).

The degree of mitochondrial DNA methylation was quantitated by scanning the PCR band density. Clearly, significant mtDNA hypomethylation was observed in cells following senescence (Figure 3(e)).

\subsection{Differential mtDNA Methylation Affects COX1 Expression.} CpG island 4 is located within the $3^{\prime}$-region of the mitochondrial COXl gene (Figure 4(a)), which encodes cytochrome c oxidase I, a key enzyme in aerobic metabolism. As the degree of mtDNA methylation at CpG 4 declines following senescence, we suspected that COX1 expression would be affected by this epigenetic regulation. We used RT-PCR to semiquantitate COX1 and found that a significant upregulation of COX1 was associated with senescence (Figure 4(b)). ND2, a second mitochondrial gene located downstream of $\mathrm{CpG}$ island 2, was slightly decreased in senescent MSCs. Similarly, the activity of the COX1 enzyme was also increased in senescent MSCs cultured from fetal heart and skin tissues (Figure 4(c)). Thus, altered mtDNA methylation may be accompanied by subtle changes in the activity of mitochondrial enzymes.

3.5. Knockdown of DNA Methyltransferases Upregulates Mitochondrial COX1. Since mtDNA becomes hypomethylated during senescence, we examined the role of three DNA methyltransferases (DNMT1, DNMT3A, and DNMT3B) that control DNA methylation. We found that all three enzymes were downregulated in senescent MSCs (Figure 5(a)).

To confirm the role of DNA methyltransferases in senescence, we knocked down the enzymes with shRNAs (Figure 5(b)). Interestingly, knockdown of these three enzymes induced senescence and inhibited cell proliferation in MSCs (Figure 5(c)), in parallel with the upregulation of COX1 (Figure 5(d)).

\section{Discussion}

The mechanisms underlying the loss of regenerative potential of the fetal heart during postnatal life remain to be illustrated. 


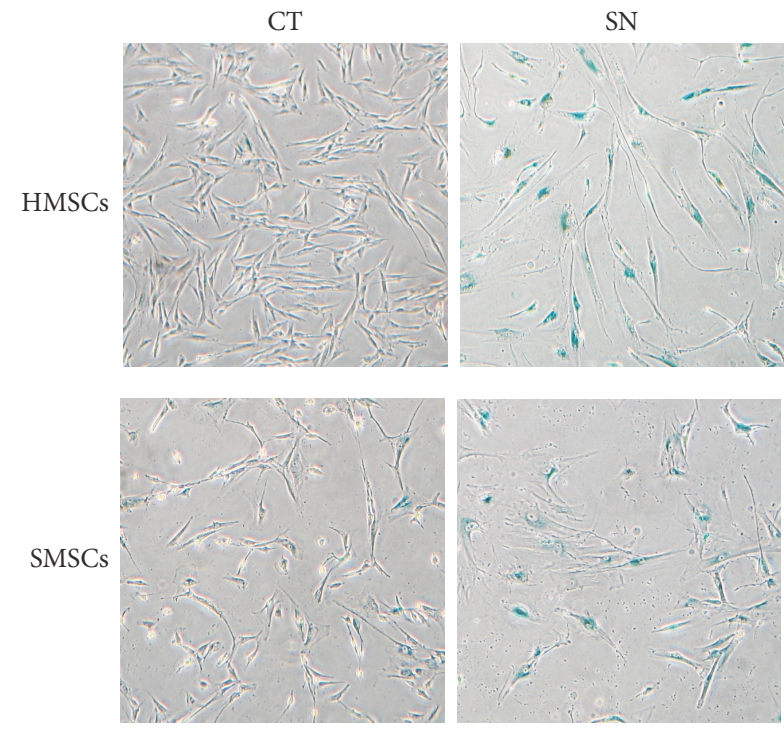

(a) $\beta$-Gal staining

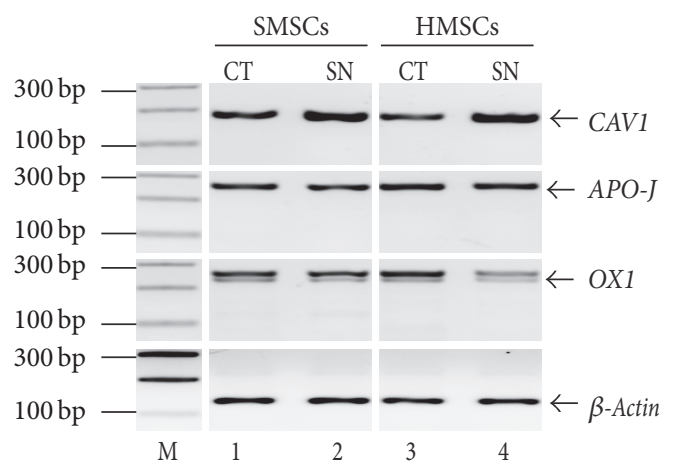

(c) Senescence gene

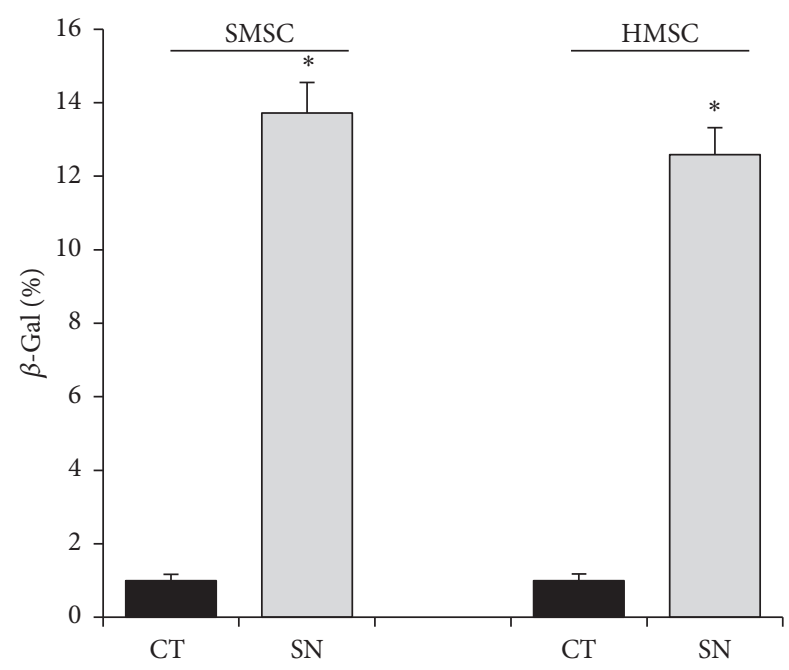

(b) $\beta$-Gal quantitation

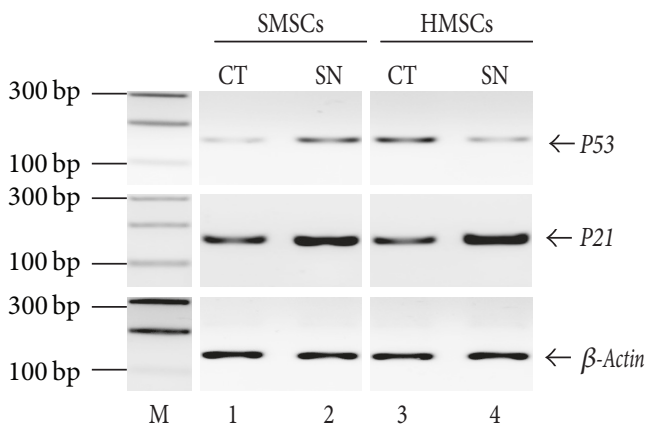

(d) Apoptosis gene

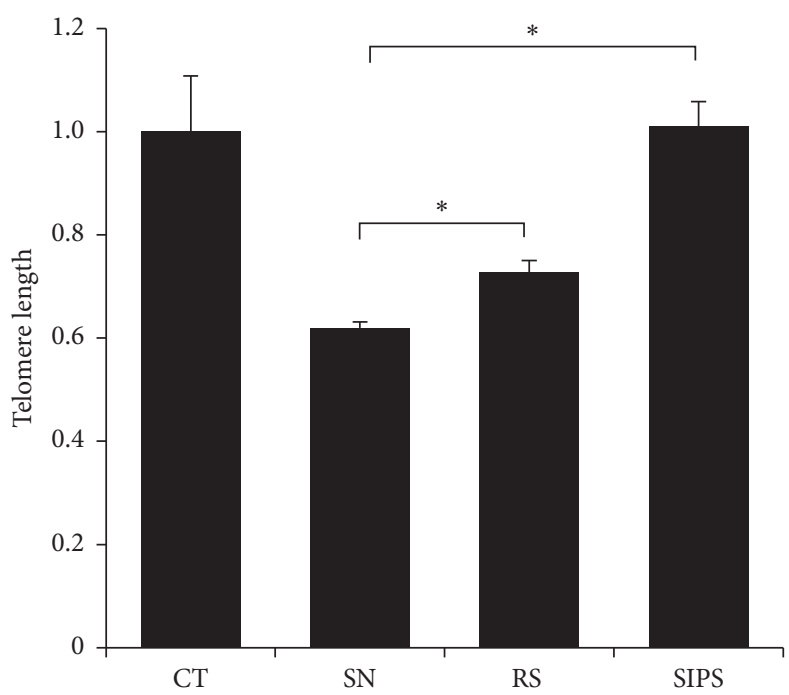

(e) Telomere length

FIGURE 2: Induction of premature senescence in MSCs. (a) Induced senescence in MSCs. Senescence was induced by continuous exposure of HMSCs (heart-derived MSCs) and SMSCs (skin-derived MSCs) to a low dose of $\mathrm{H}_{2} \mathrm{O}_{2}(50 \mu \mathrm{M})$ and low serum (5\% FBS) in the culturing medium. CT: control HMSCs treated with PBS; SN: senescent HMSCs treated with $50 \mu \mathrm{M} \mathrm{H}_{2} \mathrm{O}_{2}$ for $14 \mathrm{~d}(\times 10)$. (b) Quantitation of $\beta$-Gal cells. Cells were counted under microscopy. The results are expressed as the mean \pm standard deviation of $\beta$-Gal positive cells per field. ${ }^{*} P<0.05$ as compared with the PBS control. (c) Senescent-related genes. Senescent HMSCs were harvested and RNA were extracted. RT-PCR was carried out to amplify senescence-related genes, including caveolin-1, apolipoprotein J, and OX 1. (d) Apoptosis-related genes. Expression of p53 and p21 genes was measured by RT-PCR. (e) Telomere length in senescent HMSCs. The relative length of telomere was estimated by qPCR as the ratio between the copies of telomere and the copies of $\beta$-globin $(\mathrm{T} / \mathrm{S}) .{ }^{*} \mathrm{P}<0.05$ as compared with the replicative senescence and high $\mathrm{H}_{2} \mathrm{O}_{2}$ groups. 


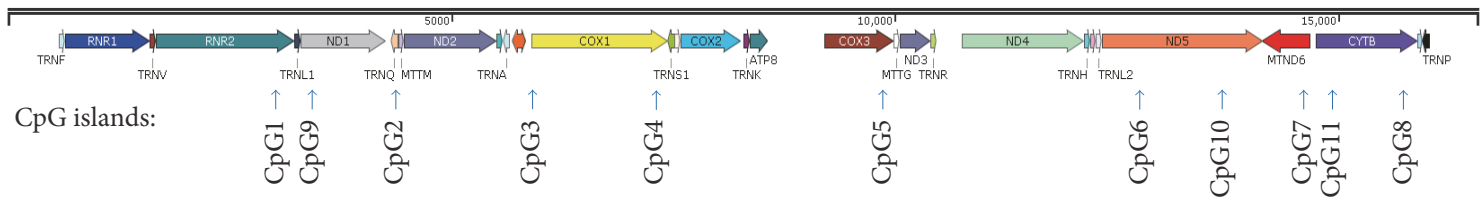

(a) mtDNA CpG islands
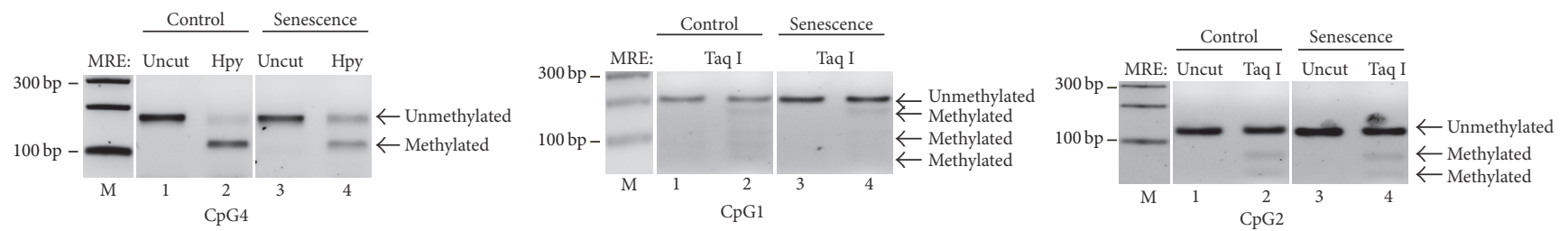

(b) mtDNA methylation in HMSCs
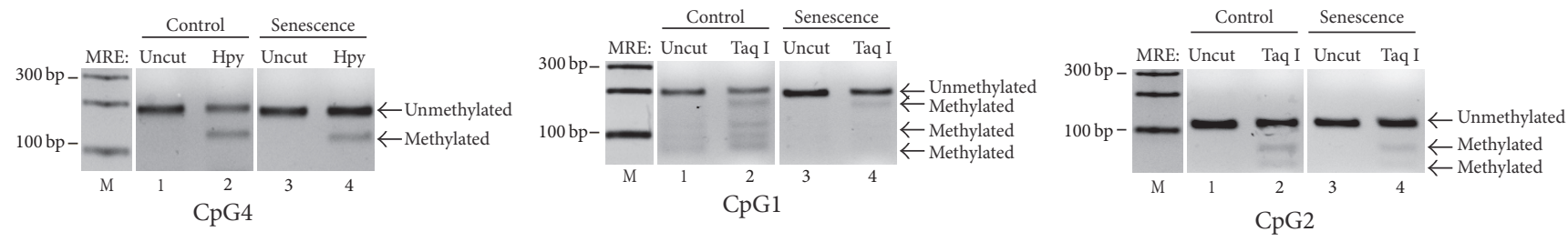

(c) mtDNA methylation in SMSCs
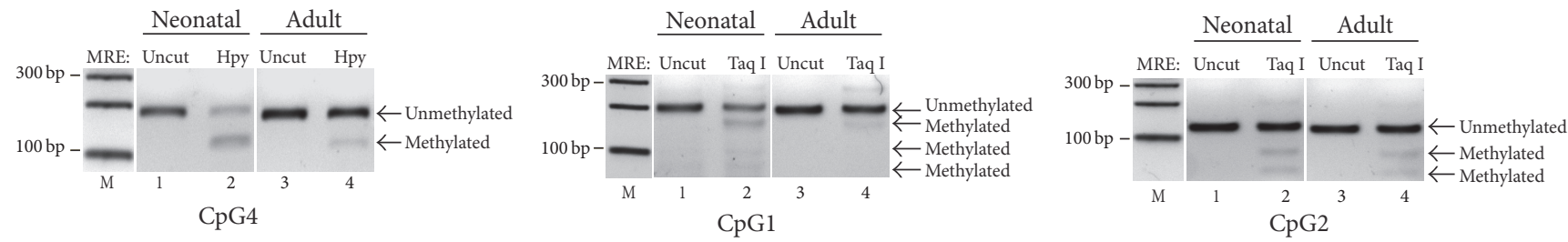

(d) mtDNA methylation in fibroblasts
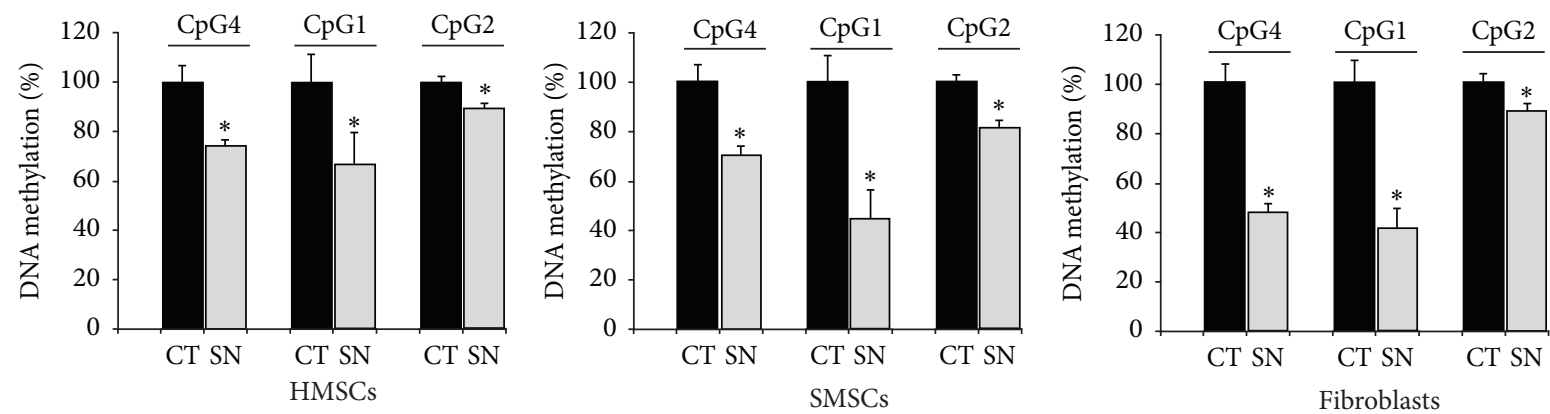

(e) Quantitation of methylation

FIGURE 3: Altered mtDNA methylation in senescent MSCs. (a) Schematic diagram of the mitochondrial genes and the location of CpG islands. In order to detect mtDNA methylation in senescent cells, we designed 11 pairs of methylation-specific primers located on different genes on mitochondrion. (b) Comparison of mtDNA methylation between the control and senescent HMSCs. mtDNA methylation was measured by combined bisulfite restriction analysis (COBRA). PCR products from mtDNA of control and senescent HMSCs were digested by TaqI or HpyCH4IV (HPY) to separate the unmethylated and methylated DNAs. Taq I and HpyCH4IV recognize and digest the methylated ACGT and TCGA sites, respectively. After treatment with sodium bisulfate, unmethylated cytosines were converted to uracils, and the TTGA and ATGT sites are not digested by these two enzymes. After digestion, unmethylated and methylated DNA were separated on $3 \%$ agarose gels. Only the data for CpG islands 4, 2, and 1 are presented here. (c) Differential mtDNA methylation between the control and senescent SMSCs. (d) Altered mtDNA methylation in human neonatal and adult fibroblasts. (e) Quantitation of mtDNA CpG methylation. The methylated and unmethylated bands were scanned. The status of $\mathrm{CpG}$ methylation was calculated as the relative percentage of DNA methylation using the untreated MSCs as $100 .{ }^{*} P<0.05$ as compared with that in untreated MSC control cells. Note the decrease in mtDNA methylation in senescent MSCs. 


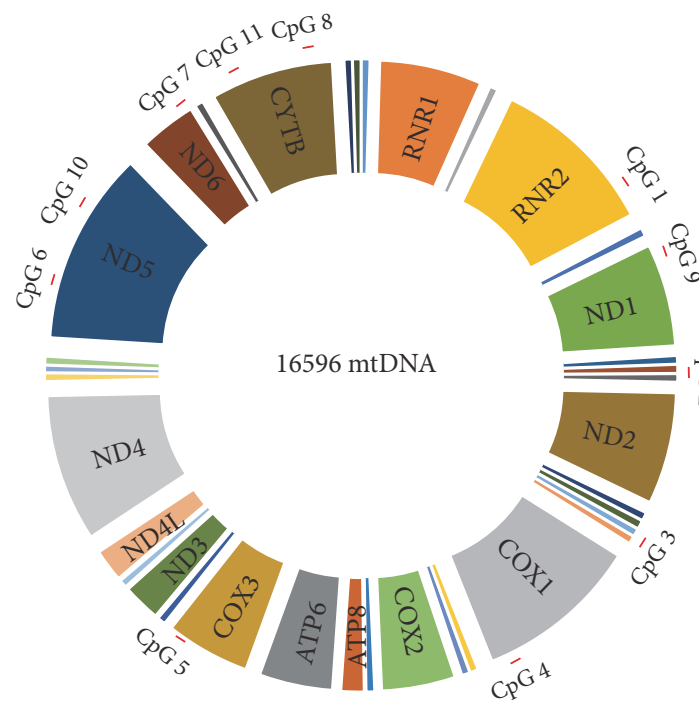

(a) CpG islands

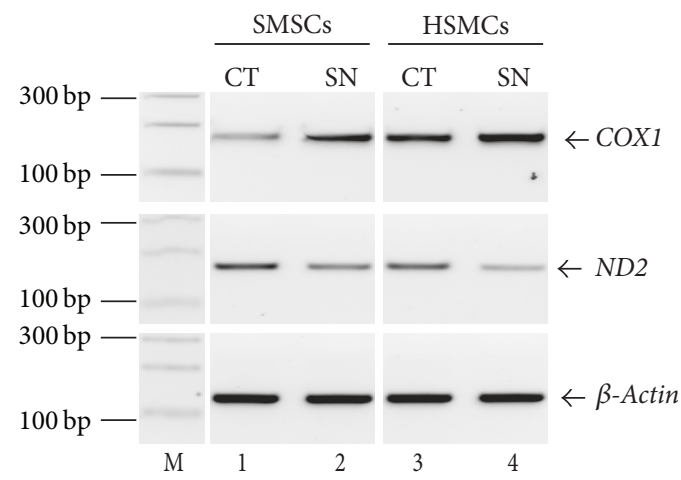

(b) Mitochondrial gene expression
Control HMSCs

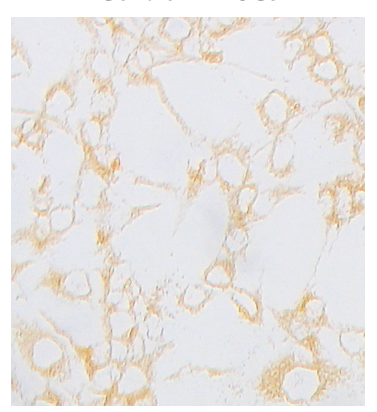

Senescent HMSCs

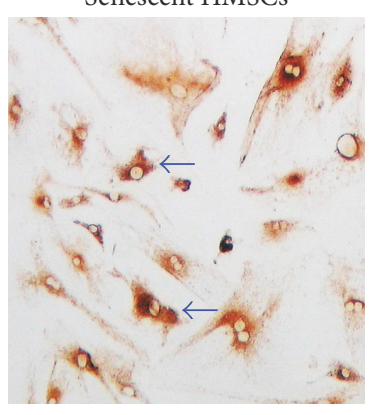

Control SMSCs

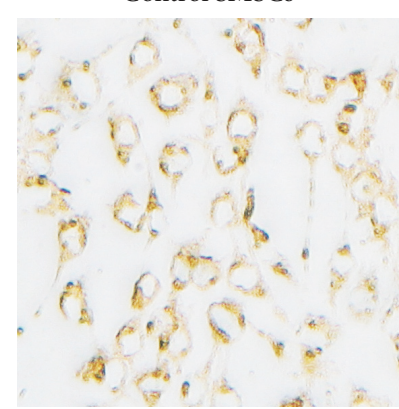

Senescent SMSCs

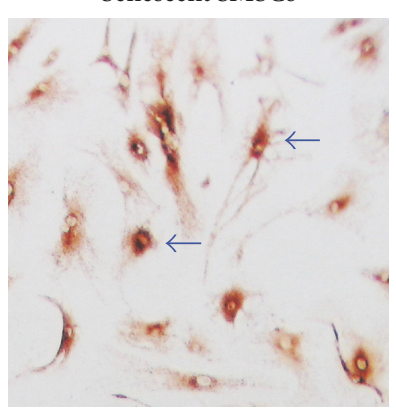

(c) COX1 activity

FIGURE 4: Alteration of mitochondrial genes during cellular senescence. (a) Location of CpG islands in the mitochondrial genome. (b) Altered gene expression of mitochondrial COX1 and ND2 genes in senescent MSCs. (c) The enzyme activity of COX1 in control and senescent MSCs.

In this study, we cultured multipotent MSCs from human fetal heart tissues and used a chronic oxidative stress/low serum approach to induce typical senescence. By scanning the status of $\mathrm{CpG}$ methylation in the whole mitochondrial genome, we demonstrated considerable mtDNA hypomethylation following senescence in MSCs. COX1, encoding the main subunit of the cytochrome $c$ oxidase complex, was significantly upregulated in senescent MSCs. Knockdown of three DNA methyltransferases (DNMT1, DNMT3a, and DNMT3B) also upregulated COX1 and induced senescence in MSCs. Together, our data suggest that mitochondrial $\mathrm{CpG}$ hypomethylation may be a useful biomarker in association with cellular senescence in MSCs.

Significant progress has been made in deciphering the regulatory pathways that control cellular senescence. There are two distinct pathways that lead to the development of cellular senescence $[47,52,53]$. Replicative senescence (RS) depends on the dysfunction in biological clock that is caused by progressive shortening of repetitive DNA sequences (TTAGGG) in telomeres that cap the ends of each chromosome. This shortening eventually triggers DNA damage and initiates a program of cell cycle arrest. In contrast, stress-induced premature senescence (SIPS), although sharing many cellular and molecular features as those undergoing replicative senescence, is telomere-independent. In SIPS, ROS induces cellular dysfunctions, playing a critical role in age-related diseases [54]. In the SIPS senescence model, oxidative stress is often used as the inducer of SIPS [55]. The cells at early passages were exposed once or several times to acute, sublethal oxidative stress, such as $\mathrm{H}_{2} \mathrm{O}_{2}$ $[56,57]$. In order to capture the characteristics of both replicative senescence and SIPS, we adopted a modified approach by exposing MSCs to a low concentration of $\mathrm{H}_{2} \mathrm{O}_{2}$ and a low serum supply. Using this strategy, we induced typical cellular senescence in MSCs within a short period of time, usually $\sim 2-3$ passages. Significantly, these senescent cells exhibit shortened telomeres. RNA-Seq confirms that the senescence is accompanied by the activation of the same pathways as seen in replicative senescence. Thus, this approach may provide an ideal model to study cellular senescence in MSCs. Future studies will be needed to comprehensively compare the gene- and protein-expression profiles of this model with two well-established SIPS and RS models. 


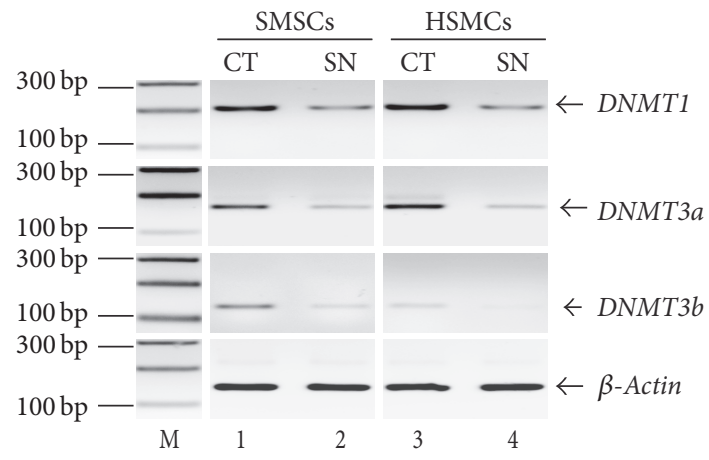

(a) Methylation enzymes

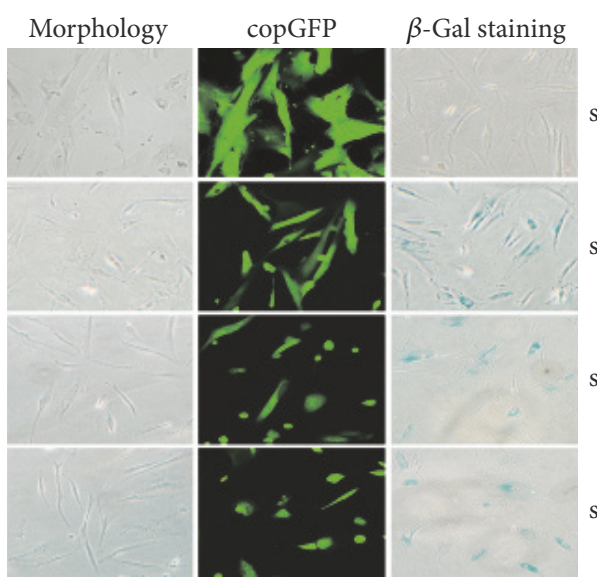

(c) $\beta$-Gal staining

sh-CT

sh-DNMT1

sh-DNMT3a

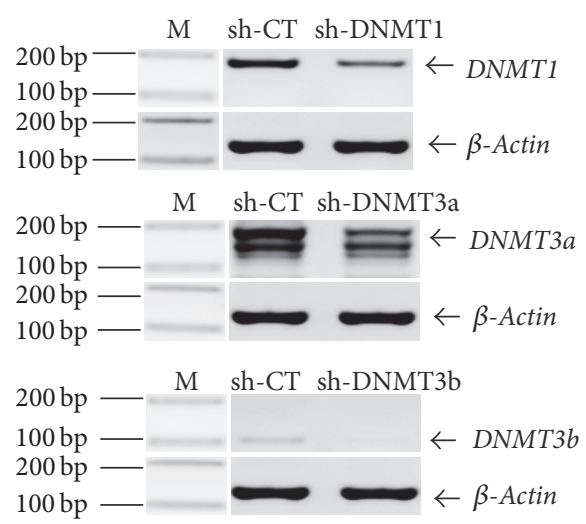

(b) shRNA knockdown

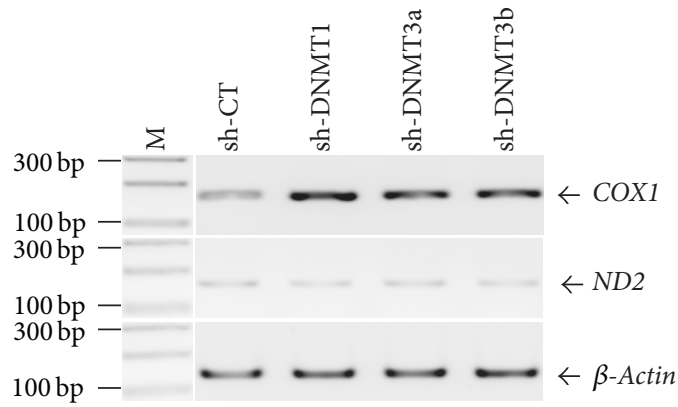

(d) Mitochondrial gene expression

Figure 5: Knockdown of DNMTs induces senescence in MSCs. (a) Downregulation of DNMTs in senescent MSCs. After induction of cellular senescence, cells were harvested and the expression of DNMTs was determined by semiquantitative PCR. (b) Knockdown of DNMTs by shRNAs. Lentiviruses containing DNMT shRNAs (sh-DNMT1, sh-SNMT3a, and sh-DNMT3b) or scramble control (sh-CT) were transduced into HMSCs. After $72 \mathrm{~h}$, transduction efficiency was assessed by the observation of GFP positive cells. Cells were harvested and RNA were extracted, and the expression of DNMTs was determined by RT-PCR. (c) Induction of cellular senescence by DNMT-shRNA knockdown. Left panel: HMSCs morphology taken 7 days after DNMT-shRNA transduction. Sh-CT: shRNA scramble control; sh-DNMTs: HMSCs were transducted by lentiviruses containing DNMT1, DNMT3a, and DNMT3b shRNAs. Middle panel: lentiviral transduction efficiency as shown by copGFP fluorescence of the shRNA vector. Right panel: senescent-associated $\beta$-Gal staining. After DNMT-shRNA knockdown, MSCs were stained for $\beta$-Gal activity. Note the occurrence of senescence in DNMT-knockdown MSCs in the absence of peroxide treatment. (d) Expression of COX and ND2 in DNMT-shRNA-treated MSCs. $\beta$-Actin was used as the internal control for PCR reaction. Cox1 was upregulated in DNMT-knockdown MSCs in parallel with cellular senescence.

Replicative senescence in culture expansion of MSC appears to be epigenetically controlled by DNA methylation and repressive histone marks at the genome DNA level [58]. However, epigenetic regulation of the mitochondrial genome in the aging of MSCs is poorly defined [30, 59]. Age-associated accumulation of mtDNA mutations has been proposed to be responsible for the age-associated mitochondrial respiration defects found in elderly human subjects. Aging phenotypes are reversible and controlled by epigenetic regulation. Reprogramming of elderly fibroblasts restores age-associated mitochondrial respiration defects [60]. We measured the status of mtDNA methylation in senescent MSCs cultured from human fetal heart tissues. Overall, the mtDNA is generally hypomethylated in senescent MSCs. This is in agreement with the extent of mtDNA methylation reported in human blood samples and lung tissues [61]. However, we noticed considerable changes in mtDNA methylation during cellular senescence. Particularly, mtDNA at CpG island 4 became more hypomethylated. This senescencerelated mtDNA demethylation was also observed in fibroblasts cultured from human adult skin as compared with those from neonatal skin tissues. Clearly, the mitochondrial genome undergoes epigenetic alterations in cellular senescence.

Accompanying the alteration of mtDNA methylation, the mitochondrial COX1 gene, which includes CpG island 4, was upregulated in all aged MSCs, as shown at both mRNA and protein enzyme levels. COX1 encodes cytochrome $\mathrm{c}$ oxidase I, the main subunit of the cytochrome $\mathrm{c}$ oxidase complex, which is a key enzyme in aerobic metabolism 
[62]. The proton pumping heme-copper oxidase represents the terminal, energy-transfer enzyme of respiratory chains in both prokaryotes and eukaryotes. Mitochondria generate adenosine $5^{\prime}$-triphosphate (ATP) but also produce potentially toxic reactive oxygen species (ROS) [59]. Gradual mitochondrial dysfunction is observed to accompany aging. Continuous accumulation of mtDNA damage may play a causal role in the aging process. However, it is unclear if the upregulated COX1 in our model is functionally involved in the initiation of senescence or it is just a sequela of the aging process.

Currently, we know little about the role that mtDNA methylation plays in the regulation of gene activity in our senescence model. For example, CpG island 4 is located in the $3^{\prime}$-region of the mitochondrial COX1 gene, rather than in the D-loop promoter region, where we might expect a $\mathrm{CpG}$ island to exert epigenetic control. However, several studies have suggested a role for gene body DNA methylation in gene regulation [63-65]. In addition, we also found that knockdown of DNA methyltransferases using shRNA induced the upregulation of COX1 in MSCs (Figure 5(d)), in parallel with cellular senescence (Figure 5(c)), in support of a role of mtDNA hypomethylation in the regulation of COX1. DNMT1, the most abundant DNA methyltransferase in mammalian cells, is the key methyltransferase required for the maintenance of DNA methylation in mammals. It predominantly catalyzes methylation at hemimethylated CpG di-nucleotides [66]. Homozygous deletion of DNMT1 is lethal for mouse embryos at 10-11 days of gestation [67]. Both DNMT3a and DNMT3b, on the other hand, are de novo methyltransferases [66]. All three enzymes are required for the establishment, maintenance, and erasure of epigenotypes, including genomic imprints, in mammalian development $[68,69]$. In our induced senescence model, these three DNMTs were downregulated in senescent MSCs (Figure 5(a)). Importantly, knockdown of DNMTs by shRNA in the absence of the oxidative stress also induced cellular senescence in MSCs (Figure 5(c)). Our data thus suggest that all three DNMTs are involved in senescence of MSCs. It should be noted that knockdown of DNMTs by shRNA also induces global DNA demethylation, including genomic DNAs. In addition, it is not clear whether mtDNA hypomethylation is a specific biomarker for our model. Particularly, we do not know if it also might occur in the replicative senescence and SIPS models. Future studies need to be performed by comparing the epigenetics of mitochondrial DNA in these models. We can learn more about epigenetic control using site-specific de novo DNA methylation or demethylation that can be induced by the CRISPR Cas9-Sss1 epigenetic regulators [43].

\section{Conclusions}

In summary, by scanning DNA methylation in mitochondrial genome, we demonstrate the association of aberrant epigenetics with the occurrence of senescence in MSCs. The alteration of mtDNA methylation is accompanied by the upregulation of COX1 gene in both senescent MSCs and the DNMT-knocked down MSCs. This study thus implicates the mtDNA epigenotype as a critical biomarker in cellular senescence of MSCs.

\section{Abbreviations \\ MSCs: Mesenchymal stem cells \\ mtDNA: Mitochondrial DNA \\ DNMT: DNA methyltransferase \\ CpG: Regions of DNA where a cytosine nucleotide is followed by a guanine nucleotide separated by only one phosphate.}

\section{Competing Interests}

The authors declare that they have no competing interests.

\section{Authors' Contributions}

All authors read and approved the final manuscript.

\section{Acknowledgments}

This work was supported by a seed grant from The Glenn Laboratories for the Biology of Aging to Andrew R. Hoffman; the National Natural Science Foundation of China Grant (81272294, 31430021), the National Basic Research Program of China (973 Program) (2015CB943303), and California Institute of Regenerative Medicine (CIRM) Grant (RT2-01942) to Ji-Fan Hu; the National Natural Science Foundation of China Grant $(81372835,81670143)$ and Jilin Science and Technique International Collaboration Grant (20130413010GH) to Wei $\mathrm{Li}$; the grant of Key Project of Chinese Ministry of Education (311015) to Jiuwei Cui; NIH Grant 1RO1ES020812 to Pinchas Cohen; and the National Natural Science Foundation of China Grant (81302380) and Development Foundation for Youths of Jilin Provincial Science \& Technology Department Grant (20140520017JH) to Dehai Yu.

\section{References}

[1] E. R. Porrello and E. N. Olson, "A neonatal blueprint for cardiac regeneration," Stem Cell Research, vol. 13, no. 3, pp. 556-570, 2014.

[2] E. R. Porrello, A. I. Mahmoud, E. Simpson et al., "Transient regenerative potential of the neonatal mouse heart," Science, vol. 331, no. 6020, pp. 1078-1080, 2011.

[3] J. J. H. Chong, V. Chandrakanthan, M. Xaymardan et al., "Adult cardiac-resident MSC-like stem cells with a proepicardial origin," Cell Stem Cell, vol. 9, no. 6, pp. 527-540, 2011.

[4] L. Tirosh-Finkel, A. Zeisel, M. Brodt-Ivenshitz et al., "BMPmediated inhibition of FGF signaling promotes cardiomyocyte differentiation of anterior heart field progenitors," Development, vol. 137, no. 18, pp. 2989-3000, 2010.

[5] B. Kloesel, J. A. Dinardo, and S. C. Body, "Cardiac embryology and molecular mechanisms of congenital heart disease: a primer for anesthesiologists," Anesthesia and Analgesia, vol. 123, no. 3, pp. 551-569, 2016. 
[6] M. J. Birket and C. L. Mummery, "Pluripotent stem cell derived cardiovascular progenitors-a developmental perspective," Developmental Biology, vol. 400, no. 2, pp. 169-179, 2015.

[7] F. Greulich, C. Rudat, and A. Kispert, "Mechanisms of T-box gene function in the developing heart," Cardiovascular Research, vol. 91, no. 2, pp. 212-222, 2011.

[8] J. H. van Weerd and V. M. Christoffels, "The formation and function of the cardiac conduction system," Development, vol. 143, no. 2, pp. 197-210, 2016.

[9] Y. Wang, X. Chen, W. Cao, and Y. Shi, "Plasticity of mesenchymal stem cells in immunomodulation: pathological and therapeutic implications," Nature Immunology, vol. 15, no. 11, pp. 1009-1016, 2014.

[10] M. T. Sutton and T. L. Bonfield, "Stem cells: innovations in clinical applications," Stem Cells International, vol. 2014, Article ID 516278, 9 pages, 2014.

[11] B. Amorin, A. P. Alegretti, V. Valim et al., "Mesenchymal stem cell therapy and acute graft-versus-host disease: a review," Human Cell, vol. 27, no. 4, pp. 137-150, 2014.

[12] F. Barry and M. Murphy, "Mesenchymal stem cells in joint disease and repair," Nature Reviews Rheumatology, vol. 9, no. 10, pp. 584-594, 2013.

[13] V. Mundra, I. C. Gerling, and R. I. Mahato, "Mesenchymal stem cell-based therapy," Molecular Pharmaceutics, vol. 10, no. 1, pp. 77-89, 2013.

[14] R. A. Pelekanos, J. Li, M. Gongora et al., "Comprehensive transcriptome and immunophenotype analysis of renal and cardiac MSC-like populations supports strong congruence with bone marrow MSC despite maintenance of distinct identities," Stem Cell Research, vol. 8, no. 1, pp. 58-73, 2012.

[15] D. N. Silva, B. S. De Freitas Souza, C. M. Azevedo et al., "Intramyocardial transplantation of cardiac mesenchymal stem cells reduces myocarditis in a model of chronic Chagas disease cardiomyopathy," Stem Cell Research and Therapy, vol. 5, no. 4, article no. 81, 2014.

[16] G. V. N. Srikanth, N. K. Tripathy, and S. Nityanand, "Fetal cardiac mesenchymal stem cells express embryonal markers and exhibit differentiation into cells of all three germ layers," World Journal of Stem Cells, vol. 5, no. 1, pp. 26-33, 2013.

[17] A. I. Hoch and J. Kent Leach, "Concise review: Optimizing expansion of bone marrow mesenchymal stem/stromal cells for clinical applications," Stem Cells Translational Medicine, vol. 3, no. 5, pp. 643-652, 2014.

[18] A. Bajek, M. Czerwinski, J. Olkowska, N. Gurtowska, T. Kloskowski, and T. Drewa, "Does aging of mesenchymal stem cells limit their potential application in clinical practice?" Aging Clinical and Experimental Research, vol. 24, no. 5, pp. 404-411, 2012.

[19] K. Książek, "A comprehensive review on mesenchymal stem cell growth and senescence," Rejuvenation Research, vol. 12, no. 2, pp. 105-116, 2009.

[20] J. D. Kretlow, Y.-Q. Jin, W. Liu et al., "Donor age and cell passage affects differentiation potential of murine bone marrow-derived stem cells," BMC Cell Biology, vol. 9, article 60, 2008.

[21] M. P. Valyushina and L. B. Buravkova, "Age-related differences in rat multipotent mesenchymal stromal bone marrow cells," Bulletin of Experimental Biology and Medicine, vol. 155, no. 1, pp. 129-133, 2013.

[22] M. Zaim, S. Karaman, G. Cetin, and S. Isik, "Donor age and long-term culture affect differentiation and proliferation of human bone marrow mesenchymal stem cells," Annals of Hematology, vol. 91, no. 8, pp. 1175-1186, 2012.
[23] Z.-Y. Zhang, S.-H. Teoh, M. S. K. Chong et al., "Superior osteogenic capacity for bone tissue engineering of fetal compared with perinatal and adult mesenchymal stem cells," Stem Cells, vol. 27, no. 1, pp. 126-137, 2009.

[24] A. Stolzing, E. Jones, D. McGonagle, and A. Scutt, "Age-related changes in human bone marrow-derived mesenchymal stem cells: consequences for cell therapies," Mechanisms of Ageing and Development, vol. 129, no. 3, pp. 163-173, 2008.

[25] M. A. Babizhayev and Y. E. Yegorov, "Tissue formation and tissue engineering through host cell recruitment or a potential injectable cell-based biocomposite with replicative potential: molecular mechanisms controlling cellular senescence and the involvement of controlled transient telomerase activation therapies," Journal of Biomedical Materials Research Part A, vol. 103, no. 12, pp. 3993-4023, 2015.

[26] T. A. Weber and A. S. Reichert, "Impaired quality control of mitochondria: aging from a new perspective," Experimental Gerontology, vol. 45, no. 7-8, pp. 503-511, 2010.

[27] D. V. Ziegler, C. D. Wiley, and M. C. Velarde, "Mitochondrial effectors of cellular senescence: beyond the free radical theory of aging," Aging Cell, vol. 14, no. 1, pp. 1-7, 2015.

[28] E. E. Hong, A. D. Smith, C. Y. Okitsu, and C.-L. Hsieh, "Regionally specific and genome-wide analyses conclusively demonstrate the absence of CpG methylation in human mitochondrial DNA," Molecular and Cellular Biology, vol. 33, no. 14, pp. 2683-2690, 2013.

[29] S. Dzitoyeva, H. Chen, and H. Manev, "Effect of aging on 5hydroxymethylcytosine in brain mitochondria," Neurobiology of Aging, vol. 33, no. 12, pp. 2881-2891, 2012.

[30] V. Iacobazzi, A. Castegna, V. Infantino, and G. Andria, "Mitochondrial DNA methylation as a next-generation biomarker and diagnostic tool," Molecular Genetics and Metabolism, vol. 110, no. 1-2, pp. 25-34, 2013.

[31] M. Jin, Y. Chen, Y. Zhou et al., "Transplantation of bone marrow-derived mesenchymal stem cells expressing elastin alleviates pelvic floor dysfunction," Stem Cell Research \& Therapy, vol. 7, no. 1, article 51, 2016.

[32] G. Chen, A. Yue, Z. Ruan et al., "Comparison of biological characteristics of mesenchymal stem cells derived from maternalorigin placenta and Wharton's jelly," Stem Cell Research and Therapy, vol. 6, no. 1, article no. 228, 2015.

[33] Z. Liu, F. Meng, C. Li et al., "Human umbilical cord mesenchymal stromal cells rescue mice from acetaminophen-induced acute liver failure," Cytotherapy, vol. 16, no. 9, pp. 1207-1219, 2014.

[34] J. Gan, F. Meng, X. Zhou et al., "Hematopoietic recovery of acute radiation syndrome by human superoxide dismutase-expressing umbilical cord mesenchymal stromal cells," Cytotherapy, vol. 17, no. 4, pp. 403-417, 2015.

[35] Y. Tang, Q. Li, F. Meng et al., "Therapeutic potential of hgfexpressing human umbilical cord mesenchymal stem cells in mice with acute liver failure," International Journal of Hepatology, vol. 2016, Article ID 5452487, 13 pages, 2016.

[36] S. Hänzelmann, F. Beier, E. G. Gusmao et al., "Replicative senescence is associated with nuclear reorganization and with dna methylation at specific transcription factor binding sites," Clinical Epigenetics, vol. 7, article no. 19, 2015.

[37] A. Schellenberg, S. Joussen, K. Moser et al., "Matrix elasticity, replicative senescence and DNA methylation patterns of mesenchymal stem cells," Biomaterials, vol. 35 , no. 24, pp. 63516358, 2014. 
[38] Y. Zhai, X. Chen, D. Yu et al., "Histone deacetylase inhibitor valproic acid promotes the induction of pluripotency in mouse fibroblasts by suppressing reprogramming-induced senescence stress," Experimental Cell Research, vol. 337, no. 1, pp. 61-67, 2015.

[39] X. Chen, Y. Zhai, D. Yu, J. Cui, J.-F. Hu, and W. Li, "Valproic acid enhances iPSC induction from human bone marrowderived cells through the suppression of reprogramminginduced senescence," Journal of Cellular Physiology, vol. 231, no. 8, pp. 1719-1727, 2016.

[40] A. Saferali, J. Lee, D. D. Sin, F. N. Rouhani, M. L. Brantly, and A. J. Sandford, "Longer telomere length in COPD patients with $\alpha 1$ - antitrypsin deficiency independent of lung function," PLoS ONE, vol. 9, no. 4, Article ID e95600, 2014.

[41] F. El Bouazzaoui, P. Henneman, P. Thijssen et al., "Adipocyte telomere length associates negatively with adipocyte size, whereas adipose tissue telomere length associates negatively with the extent of fibrosis in severely obese women," International Journal of Obesity, vol. 38, no. 5, pp. 746-749, 2014.

[42] S. Marthandan, M. Baumgart, S. Priebe et al., "Conserved senescence associated genes and pathways in primary human fibroblasts detected by RNA-seq," PLoS ONE, vol. 11, no. 5, 2016.

[43] A.-N. Ma, H. Wang, R. Guo et al., "Targeted gene suppression by inducing de novo DNA methylation in the gene promoter," Epigenetics and Chromatin, vol. 7, no. 1, article no. 20, 2014.

[44] X. Zhao, X. Liu, G. Wang et al., "Loss of insulin-like growth factor II imprinting is a hallmark associated with enhanced chemo/radiotherapy resistance in cancer stem cells," Oncotarget, vol. 7, no. 32, pp. 51349-51364, 2016.

[45] S. Zhang, B. Zhong, M. Chen et al., "Epigenetic reprogramming reverses the malignant epigenotype of the MMP/TIMP axis genes in tumor cells," International Journal of Cancer, vol. 134, no. 7, pp. 1583-1594, 2014.

[46] J. Sun, W. Li, Y. Sun et al., "A novel antisense long noncoding RNA within the IGF1R gene locus is imprinted in hematopoietic malignancies," Nucleic acids research, vol. 42, no. 15, pp. 95889601, 2014.

[47] A. Bernadotte, V. M. Mikhelson, and I. M. Spivak, "Markers of cellular senescence. Telomere shortening as a marker of cellular senescence," Aging, vol. 8, no. 1, pp. 3-11, 2016.

[48] E. Sikora, A. Bielak-Zmijewska, and G. Mosieniak, "Cellular senescence in ageing, age-related disease and longevity," Current Vascular Pharmacology, vol. 12, no. 5, pp. 698-706, 2014.

[49] N. Ishikawa, K.-I. Nakamura, N. Izumiyama-Shimomura et al., "Changes of telomere status with aging: an update," Geriatrics and Gerontology International, vol. 16, pp. 30-42, 2016.

[50] L. Matos, A. Gouveia, and H. Almeida, "Copper ability to induce premature senescence in human fibroblasts," Age, vol. 34, no. 4, pp. 783-794, 2012.

[51] M. Purcell, A. Kruger, and M. A. Tainsky, "Gene expression profiling of replicative and induced senescence," Cell Cycle, vol. 13, no. 24, pp. 3927-3937, 2014.

[52] T. Chandra and K. Kirschner, "Chromosome organisation during ageing and senescence," Current Opinion in Cell Biology, vol. 40, pp. 161-167, 2016.

[53] I. Fridlyanskaya, L. Alekseenko, and N. Nikolsky, "Senescence as a general cellular response to stress: a mini-review," Experimental Gerontology, vol. 72, pp. 124-128, 2015.

[54] J. Chen, S. Patschan, and M. S. Goligorsky, "Stress-induced premature senescence of endothelial cells," Journal of Nephrology, vol. 21, no. 3, pp. 337-344, 2008.
[55] U. K. Rajarajacholan and K. Riabowol, "Aging with ING: a comparative study of different forms of stress induced premature senescence," Oncotarget, vol. 6, no. 33, pp. 34118-34127, 2015.

[56] K. B. U. Choo, L. Tai, K. S. Hymavathee et al., "Oxidative stressinduced premature senescence in Wharton's jelly-derived mesenchymal stem cells," International Journal of Medical Sciences, vol. 11, no. 11, pp. 1201-1207, 2014.

[57] M. J. Choi, B. K. Kim, K. Y. Park, T. Yokozawa, Y. O. Song, and E. J. Cho, "Anti-aging effects of cyanidin under a stressinduced premature senescence cellular system," Biological and Pharmaceutical Bulletin, vol. 33, no. 3, pp. 421-426, 2010.

[58] A. Schellenberg, Q. Lin, H. Schüler et al., "Replicative senescence of mesenchymal stem cells causes DNA-methylation changes which correlate with repressive histone marks," Aging, vol. 3, no. 9, pp. 873-888, 2011.

[59] Y. Wang and S. Hekimi, "Mitochondrial dysfunction and longevity in animals: untangling the knot," Science, vol. 350, no. 6265, pp. 1204-1207, 2015.

[60] O. Hashizume, S. Ohnishi, T. Mito et al., "Epigenetic regulation of the nuclear-coded GCAT and SHMT2 genes confers human age-associated mitochondrial respiration defects," Scientific Reports, vol. 5, Article ID 10434, 2015.

[61] B. Liu, Q. Du, L. Chen et al., "CpG methylation patterns of human mitochondrial DNA," Scientific Reports, vol. 6, Article ID 23421, 2016.

[62] S. Dennerlein and P. Rehling, "Human mitochondrial COX1 assembly into cytochrome c oxidase at a glance," Journal of Cell Science, vol. 128, no. 5, pp. 833-837, 2015.

[63] D. Jjingo, A. B. Conley, S. V. Yi, V. V. Lunyak, and I. King Jordan, "On the presence and role of human gene-body DNA methylation," Oncotarget, vol. 3, no. 4, pp. 462-474, 2012.

[64] A. Hellman and A. Chess, "Gene body-specific methylation on the active X chromosome," Science, vol. 315, no. 5815, pp. 1141$1143,2007$.

[65] M. P. Ball, J. B. Li, Y. Gao et al., "Targeted and genome-scale strategies reveal gene-body methylation signatures in human cells," Nature Biotechnology, vol. 27, no. 4, pp. 361-368, 2009.

[66] T. Hamidi, A. K. Singh, and T. Chen, "Genetic alterations of DNA methylation machinery in human diseases," Epigenomics, vol. 7, no. 2, pp. 247-265, 2015.

[67] E. Li, T. H. Bestor, and R. Jaenisch, "Targeted mutation of the DNA methyltransferase gene results in embryonic lethality," Cell, vol. 69, no. 6, pp. 915-926, 1992.

[68] J. R. Weaver, M. Susiarjo, and M. S. Bartolomei, "Imprinting and epigenetic changes in the early embryo," Mammalian Genome, vol. 20, no. 9-10, pp. 532-543, 2009.

[69] F. Uysal, G. Akkoyunlu, and S. Ozturk, "Dynamic expression of DNA methyltransferases (DNMTs) in oocytes and early embryos," Biochimie, vol. 116, pp. 103-113, 2015. 

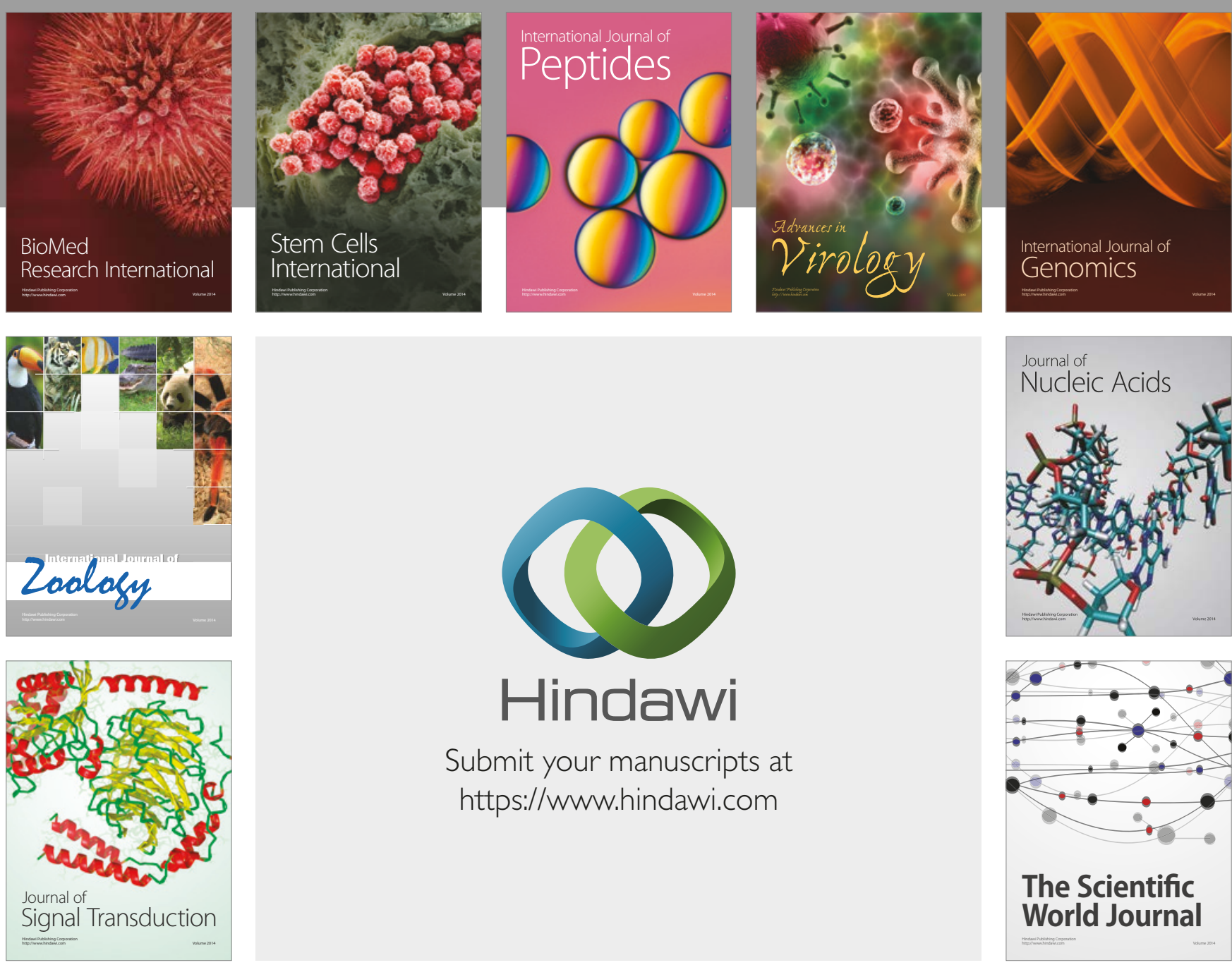

Submit your manuscripts at

https://www.hindawi.com
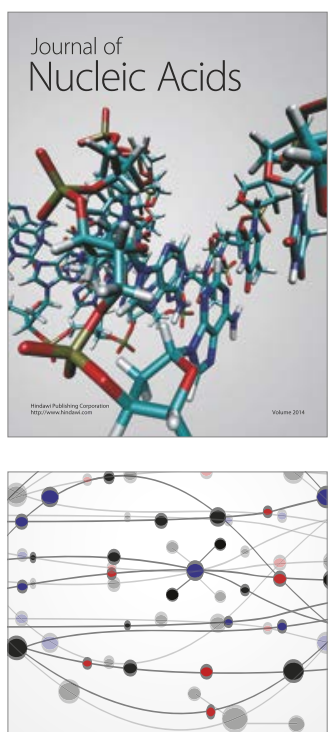

The Scientific World Journal

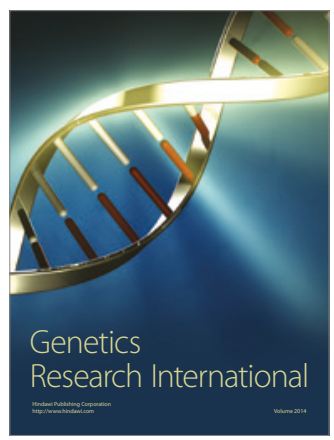

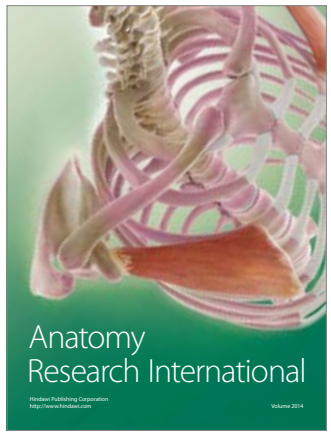

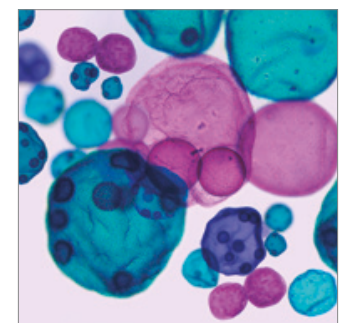

International Journal of Microbiology
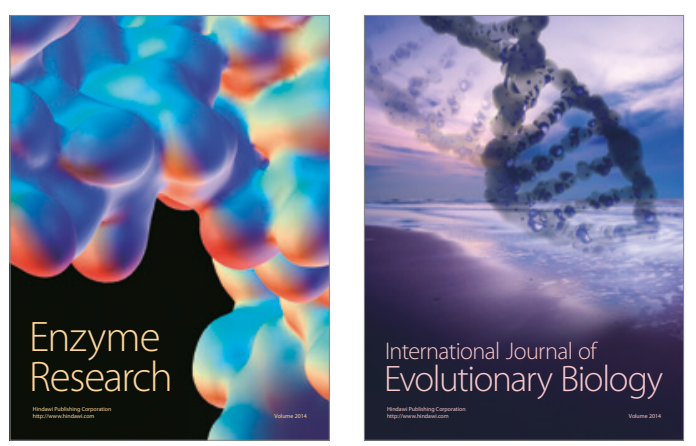
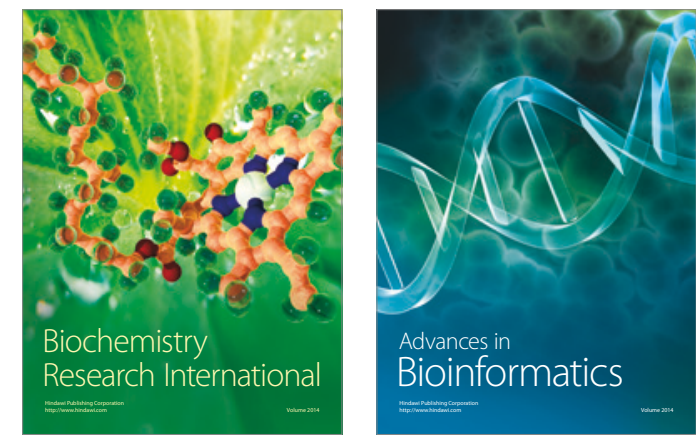

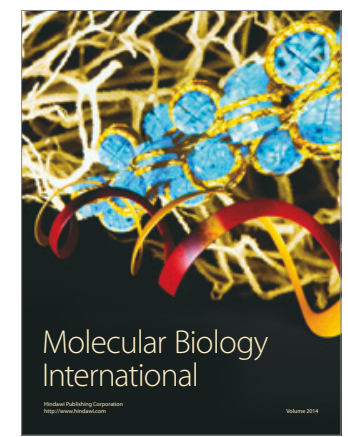

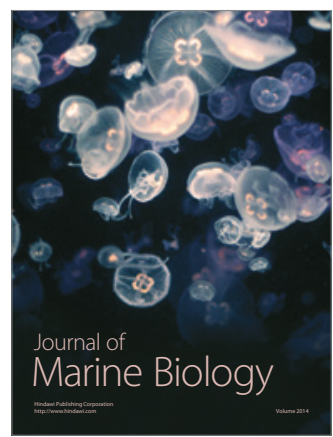

